\title{
Risk of Osteoporotic Fracture in Patients with Breast Cancer: Meta-Analysis
}

\author{
Seeyoun Lee ${ }^{1, *}$, Jun-II Yoo ${ }^{2, *}$, Young-Kyun Lee ${ }^{3}$, Jung-Wee Park ${ }^{3}$, Seokhyung Won ${ }^{3}$, Jiung Yeom ${ }^{3}$, Jin Woo Im³, \\ Seok Min Lim³, Yong-Chan $\mathrm{Ha}^{4}$, Kyung-Hoi Koo ${ }^{3}$ \\ 'Department of Surgery, Center for Breast Cancer, Research Institute and Hospital, National Cancer Center, Goyang; \\ ${ }^{2}$ Department of Orthopaedic Surgery, Gyeongsang National University Hospital, Jinju; \\ ${ }^{3}$ Department of Orthopaedic Surgery, Seoul National University Bundang Hospital, Seoul National University College of Medicine, \\ Seongnam; \\ ${ }^{4}$ Department of Orthopaedic Surgery, Chung-Ang University College of Medicine, Seoul, Korea
}

\section{Corresponding author \\ Young-Kyun Lee \\ Department of Orthopaedic Surgery, Seoul \\ National University Bundang Hospital, Seoul \\ National University College of Medicine, \\ 82 Gumi-ro 173 beon-gil, Bundang-gu, \\ Seongnam 13620, Korea \\ Tel: +82-31-787-7204 \\ Fax: +82-31-787-4056 \\ E-mail: ykleemd@gmail.com}

Received: December 12, 2019

Revised: January 5, 2020

Accepted: January 9, 2020

*Seeyoun Lee and Jun-II Yoo contributed equally to this work and should be considered co-first authors.

Copyright (C) 2020 The Korean Society for Bone and Mineral Research

This is an Open Access article distributed under the terms of the Creative Commons Attribution Non-Commercial License (https://creativecommons.org/licenses/by-nc/4.0/) which permits unrestricted non-commercial use, distribution, and reproduction in any medium, provided the original work is properly cited.

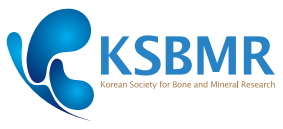

Background: The fracture risk induced by anti-estrogen therapy in patients with breast cancer remains controversial. The aim of this study was to perform a meta-analysis and systematic review to evaluate the risk of osteoporotic fracture in patients with breast cancer. Methods: A systematic search was performed to identify studies that included any osteoporotic fracture (hip fracture and vertebral fracture) in patients breast cancer. Main outcome measures were occurrence and risk of osteoporotic fractures including hip and vertebral fractures in patients and controls. Results: A systematic search yielded a total of 4 studies that included osteoporotic fracture outcomes in patients with breast cancer. Meta-analysis showed a higher risk of osteoporotic fracture in patients with breast cancer. Analysis of these 4 studies involving a total of 127,722 (23,821 cases and 103,901 controls) patients showed that the incidence of osteoporotic fractures was higher in the breast cancer group than in the control group. The pooled estimate of crude relative risk for osteoporotic fracture was 1.35 (95\% confidence interval, 1.29-1.42; $P<0.001)$. Conclusions: Although studies were limited by a small number, results suggested a possible association between anti-estrogen therapy and increased risk of osteoporotic fractures in patients with breast cancer.

Key Words: Breast neoplasms · Hip fractures · Osteoporotic fractures · Spinal fractures

\section{INTRODUCTION}

Breast cancer is the most commonly diagnosed cancer in women worldwide. $[1,2]$ Breast cancer has been considered as an estrogen-hormone dependent cancer because its occurrence and recurrence depend on the status of hormone and hormone receptor in cancer cells.[3] Therefore, anti-estrogen therapy using tamoxifen or aromatase inhibitors (Als) has been the gold standard adjuvant endocrine therapy to treat hormone receptor-positive breast cancer $[4,5]$ and to control recurrent or metastatic disease.[6]

Anti-estrogen therapy in breast cancer patients inhibits estrogen activity in the bone as well as breast cancer. Anti-estrogen therapy could induce negative bone balance in breast cancer patients caused by severe estrogen depletion.[7] Howev- 
er, it can significantly increase bone loss compared to physiologic postmenopausal bone loss,[8-12] thus increasing the risk of osteoporotic fractures.[13-16]

Concern about fracture risk induced by anti-estrogen therapy in breast cancer patients is increasing.[17,18] However, the fracture risk in patients with breast cancer remains controversial. Data on the fracture risk in breast cancer patients are limited. Thus, the purpose of this study was to determine the risk of osteoporotic fracture in patients with breast cancer through a systematic review and meta-analysis.

\section{METHODS}

This study was exempted from review by the institutional review board (IRB) because of its retrospective nature.

\section{Search strategy and selection criteria}

This meta-analysis was conducted according to the updated guidelines of the Preferred Reporting Items for Systematic Review and Meta-Analysis Protocols (PRISMA-P). [19] Two researchers (blinded by authors) independently searched Medline (PubMed), EMBASE, and Cochrane Library databases in September 2018. An overview of the search strategy is presented in Supplementary Appendix A. Two authors then independently screened titles and abstracts to identify studies on fractures in patients with breast cancer. They also checked reference lists of all potentially eligible studies and review papers to find additional relevant publications. Articles that met the selection criteria were included in this meta-analysis.

Studies were screened and selected by all investigators based on a priori criteria. Inclusion criteria were as follows: (1) published as an original article in English; (2) evaluated the incidence of osteoporotic fracture (hip, vertebral, distal radius, and proximal humerus) as primary outcomes; and (3) available numerical data for both cases and controls (number of patients, mean and standard deviation of age). Exclusion criteria were as follows: (1) treated for osteoporosis; (2) treated with chemotherapy or hormone replacement; and (3) a review, a case report, or an in vitro study. Two authors (YJI and LYK) reviewed the retrieved full manuscripts to determine whether osteoporotic fracture had been reported in patients with breast cancer. The primary outcome for the meta-analysis was the difference in the incidence of osteoporotic fractures. The osteoporotic fracture included any of hip, vertebral, distal radius, and proximal humerus fractures. The location of the fracture was not distinguished. For every eligible study, the following data were extracted and entered into a spreadsheet by 2 reviewers: family name of the first author, year of publication, country, number of patients, and basic characteristics of subjects (age).

\section{Statistical analysis}

The primary analysis involved a proportion meta-analysis of the data from all relevant studies that reported the incidence of osteoporotic fracture. A fixed-effects or random-effects model was used to quantify the pooled effect size of included studies, depending on the heterogeneity of the data. Heterogeneity between comparable studies was tested using $\chi^{2}$ and $I^{2}$ tests. $P>0.1$ and $I^{2}<50 \%$, respectively, were used as established criteria to determine statistical heterogeneity. All analyses were performed using STATA software, version 14.0 (Stata Corporation, College Station, TX, USA).

\section{RESULTS}

From PubMed-Medline, EMBASE, and Cochrane Library, a total of 2,161 published articles were found after searching for osteoporotic fracture in patients with breast cancer. Of these 2,161 articles, 1,915 were excluded because of duplication. A total of 204 were then excluded because they did not meet our inclusion criteria (Fig. 1). The remaining 4 studies fulfilling all inclusion criteria were reviewed.[20-23] One was from China, 1 from Taiwan, 1 from the UK, and 1 from Israel. These studies involving 127,722 participants were identified for the meta-analysis.

Fraenkel et al. [20] performed a case control cross-sectional, retrospective study to determine whether breast cancer was associated with osteoporotic fracture in 17,110 women with a BMD test between 2003 and 2011. Among 1,193 women with osteoporosis, 62 had a previous history of breast cancer while the remaining 131 did not. BMD was similar among women with and without breast cancer who had fractures. Hsieh et al. [21] performed a cross-sectional, retrospective study to compare the prevalence of vertebral fractures in 200 breast cancer women with age- and body mass index-matched women. They showed 22 (11\%) ver- 

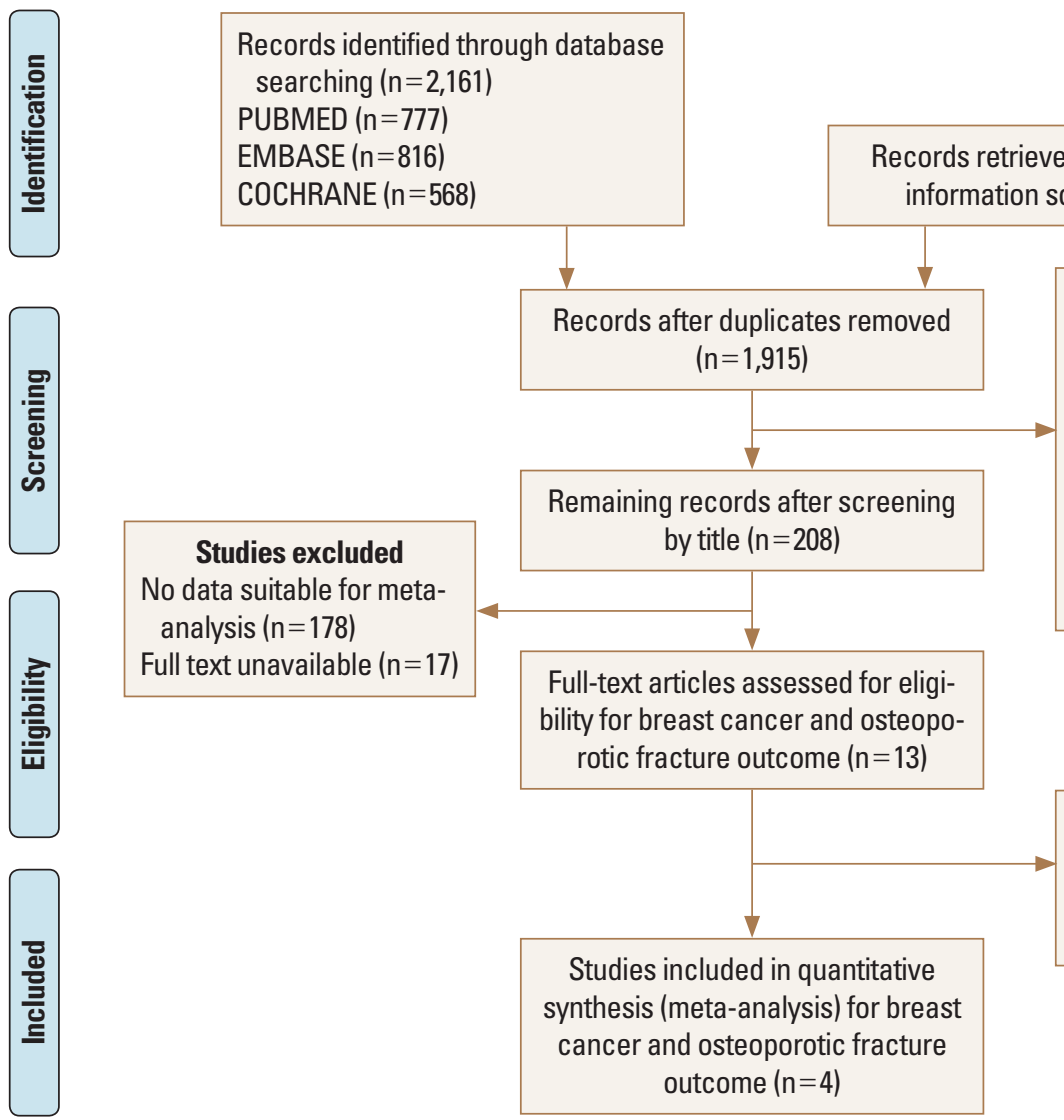

Studies excluded
Unrelated ( $n=257)$
Reviews/editorials/letters/notes/abstracts/
posters $(n=483)$
Male $(n=21)$
Osteoporosis treatment (bisphosphonate/
SERMs/Tibolone/HRT) ( $n=514)$
Breast cancer treatment ( $n=185)$
Without history of breast cancer $(n=247)$

Studies excluded

No data for osteoporotic fracture $(n=1)$ No data suitable for meta-analysis $(n=6)$ No data for bone mineral density $(n=2)$

Fig. 1. Preferred reporting items for systematic reviews and meta-analysis flow diagram showing the process of selecting relevant studies.

Table 1. Risk of osteoporotic fracture in patients with breast cancer

\begin{tabular}{|c|c|c|c|c|c|}
\hline Author & Region & Study design & Subjects & Age & Risk of fracture \\
\hline Fraenkel et al. [20] & Israel & Case control study & $\begin{array}{l}\text { 1,193 cases/ } \\
14,621 \text { controls }\end{array}$ & $\begin{array}{l}68.8 \pm 8.8 / \\
68.8 \pm 10.2\end{array}$ & Increased risk of fracture \\
\hline Hsieh et al. [21] & China & Cross-sectional study & $\begin{array}{l}200 \text { cases/ } \\
200 \text { matched controls }\end{array}$ & $\begin{array}{l}57.5 \pm 4.9 / \\
57.5 \pm 4.9\end{array}$ & Increased risk of vertebral fracture \\
\hline Kanis et al. [22] & United Kingdom & Case control study & 352 cases/776 controls & $\begin{array}{l}54.5 \pm 10.4 / \\
54.1 \pm 6.0\end{array}$ & Increased risk of vertebral fracture \\
\hline Tsai et al. [23] & Taiwan & Population-based cohort study & $\begin{array}{l}\text { 22,076 cases/ } \\
88,304 \text { controls }\end{array}$ & $\begin{array}{l}51.4 \pm 12.0 / \\
51.2 \pm 12.3\end{array}$ & Increased risk of fracture \\
\hline
\end{tabular}

tebral fractures in breast cancer survivors compared to 7 (3.5\%) vertebral fractures in the comparison group. The adjusted odds ratio (OR) for vertebral fracture was 4.16 (95\% confidence interval [Cl], 1.69-10.21; $P<0.01$ ). Kanis et al. [22] have performed a retrospective case-control study to compare the risk of vertebral fractures between women with and without breast cancer. They showed that the incidence of vertebral fracture in women with breast cancer was nearly 5 times greater than that in the control group $(\mathrm{OR}, 4.7,95 \% \mathrm{Cl}, 2.3-9.9)$ and 20-fold higher in women with soft-tissue metastases without evidence of skeletal metastases (OR, 22.7, 95\% Cl, 9.1-57.1). Tsai et al. [23] have performed a nationwide retrospective cohort study to compare the risk of osteoporotic fracture between 22,076 breast cancer patients and 88,304 controls between 2000 and 2003. They showed that the incidence of all types of fractures was higher in the breast cancer cohort than in the comparison cohort, with adjusted HRs of 1.18 (95\% Cl, 1.03-1.35) for hip fractures, 1.12 (95\% Cl, 0.98-1.28) for forearm fractures, and $1.24(95 \% \mathrm{Cl}, 1.04-1.48)$ for vertebral fractures (Table 1). 




Fig. 2. Forest plots for the effect of breast cancer on osteoporotic fractures determined by fixed effects meta-analysis.

Analysis for 4 studies involving a total of $127,722(23,821$ cases and 103,901 controls) subjects showed that the incidence of fractures was higher in breast cancer patients than in the control group. The pooled estimate of crude OR for osteoporotic fractures was $1.244(95 \% \mathrm{Cl}, 1.091-1.419 ; P=$ 0.001; Fig. 2).

\section{DISCUSSION}

Clinical implications of menopause in bone metabolism are critical because it results in loss of bone mass.[24] However, the potential adverse effect of breast cancer on bone remains controversial. Our purpose was to review the literature on the fracture risk in breast cancer patients, focusing on the reported occurrence of osteoporotic fracture. After reviewing one population-based cohort study, 1 crosssectional study, and 2 case-control studies, the fracture risk in breast cancer patients appeared to be higher than that in the general population.

Menopause with estrogen deprivation is the most important cause of osteoporosis in women. Anti-estrogen effects by tamoxifen and aromatase reductase inhibitor (ARI) commonly used to treat breast cancer may lead to menopause even in young women.[25] Although we planned to conduct a structural meta-analysis, the number of included studies was too small. However, we found that breast cancer patients showed a higher risk of osteoporotic fracture through a meta-analysis.

Current reviews have explored the linkage between postmenopausal osteoporosis and breast cancer due to increasing the prevalence of breast cancer and osteoporosis among postmenopausal women. $[26,27]$ In fact, in some postmenopausal women, osteoporosis was considered to be a lateterm effect of estrogen receptor (ER)-positive breast cancer treatment.[28] A clearer understanding of the linkage between postmenopausal osteoporosis and breast cancer could lead to the development of a therapeutic target for postmenopausal breast cancer patients. Below, we examined some biochemical linkages between postmenopausal osteoporosis and breast cancer.

Receptor activator of nuclear factor- $\mathrm{KB}$ ligand (RANKL) is an important cytokine that is a member of the tumor necrosis factor (TNF) family. It is coded for TNF ligand superfamily member 11 (TNFSF11) genes.[29] RANKL plays an important role in human physiology by regulating the differentiation and activation of bone cells called osteoclasts that are responsible for bone breakdown.[26] Osteoclasts can cause a cascade of events culminating in the removal and replacement of low bone content with new bone, preserving bone and skeletal integrity.[30] Reports have shown that when controlled, RANKL can facilitate osteoclast differentiation with subsequent initiation of excessive bone resorption, leading to loss of bone integrity.[26] Ironically, the RANKL/RANK pathway has been implicated in breast development and breast carcinogenesis. In RANK- and RANKL receptor-deficient mice, lactating mammary gland did not develop cancer.[31] In another study, the production of mammary carcinogenesis in 7,12-Dimethylbenzathraceneinduced mice was associated with increased RANKL expression.[25] Accelerated breast carcinogenesis was observed in RANK-transgenic mice.[25] These studies clearly point to the involvement of RANKL in mammary tumorigenesis, providing insights into future research that could target RANKL for hormone receptor-positive breast cancer therapy.

Bone and breast tissues are both estrogen-dependent. Previous studies have shown that high bone mineral density (BMD) is correlated with breast cancer risk.[32] Estrogen hormone is a central regulator of bone density. It maintains a balance between bone formation and bone resorption by either reducing osteoclast levels or promoting osteoblast proliferation.[33] Estrogen deficiency has been associated with a decreased BMD that is prominently seen in postmenopausal women.[34] In breast carcinogenesis, increased exposure to estrogen is correlated with early menarche, late menopause, estrogen replacement therapy, and obesity. High blood levels of estrogen can increase the risk, incidence, and severity of breast cancer in premenopausal and postmenopausal women.[35] Molecular studies on possible mechanisms by which estrogen influences breast carcinogenesis have indicated that estrogen acts on the 
$E R$, that estrogen-ER dimer binds to the estrogen-responsive component, and that transcription factors such as activator protein-1 are enabled.

In contrast, the specificity protein-1 promotes cell proliferation which ultimately causes cancer cells to spread.[36] In addition, Nishimukai et al. [37] performed study about different patterns of change in bone turnover markers during treatment with bone-modifying agents for breast cancer patients with bone metastases. They reported that tartrate-resistant acid phosphatase $5 b$ (TRACP-5b) appears to affect levels most quickly and sensitively, possibly due to its direct link to the number and activity of osteoclasts. These findings suggest that the efficacy of TRACP- $5 b$ is clinically significant when considering which bone-modifying agents to use for breast cancer patients with bone metastases.[37] Due to the role of estrogen in breast cancer, Als that are inhibitors of aromatase (estrogen metabolizing enzyme) have been used in the treatment of postmenopausal ER-positive breast cancer patients despite challenges to bone fracture in these patients.[32] Recently, scientists are investigating the potential of denosumab, an anti-RANKL antibody, to prevent bone loss associated with Als. Such studies could provide significant benefits for postmenopausal breast cancer patients.

Although reactive oxygen species (ROS) play important roles in physiological functions, overwhelming levels of ROS generation can result in oxidative stress associated with postmenopausal osteoporosis and carcinogenesis. [38] Osteoclasts recruit ROS to facilitate the catabolism of calcified tissue needed for bone remodeling.[38] Conversely, excess ROS generation results in oxidative stress and causes osteocyte apoptosis which is associated with increased turnover of bone remodeling and bone loss.[39,40] It has been shown that hydrogen peroxide can enhance osteoclast activity, further supporting the concept that oxidative stress is associated with increased bone resorption and low bone mass.[41] Studies of antioxidant ability to inhibit bone-associated disorders have shown that glutathione and $\mathrm{N}$-acetylcysteine can reduce osteocyte apoptosis and enhance RANKL expression.[42,43] For breast cancer, oxidative stress is involved in the initiation, development, and progression of breast carcinogenesis.[44] Breast tissue is a complex combination of different types of cells, including neoplasm cells and stromal cells.[45] In cancerous breast tissue, stromal fibroblasts develop a phenotype character- ized by increased levels of growth factors, cytokines, and metalloproteinases.[46] Altered redox status in favor of pro-oxidants in the tumor microenvironment can induce the development of activated fibroblasts, resulting in changes in epithelial cells which facilitate tumorigenesis.[47] Oxidative stress in the tumor microenvironment is also characterized by activated stromal cells that produce signalenhancing tumors and promote tumor growth and vascularization.[44] Oxidative stress is therefore clearly involved in both postmenopausal osteoporosis and breast cancer. Serum estrogen levels are decreased by approximately $90 \%$ at menopause.[48] In post-menopausal women, anastrozole, letrozole, and exemestane can lower serum levels of estrogen by $81 \%$ to $94 \%, 88 \%$ to $98 \%$, and $52 \%$ to $72 \%$, respectively.[49] Bone physiology is best understood when described at levels of osteoclasts, osteoblasts and osteocytes (cellular level), bone cell interaction during bone remodeling (tissue level) and bone turnover and mass or fracture incidence. At the cellular level, estrogen has profound effects on osteoblasts and osteoclasts. Estrogen decreases the osteoblastic development of resorptive cytokines including RANKL, colony-stimulating factor-1, interleukin-1, and TNF. At the same time, it increases the production of anti-receptive cytokines (mainly osteoprotegerin), leading to increased osteoclastic apoptosis and increased osteoblastic activity.[50] This results in an increase in osteoclaststimulating serum parathyroid hormone which leads to increased bone loss.[51] Nonetheless, there is only one study available on the effect of Als on osteoblast-like cells. It indicates that exemestane can enhance osteoblast behavior. [52] Considering the mechanism, additional meta-analysis related to ARI or tamoxifen is necessary.

\section{CONCLUSIONS}

Overall, our results suggested that patients with breast cancer might have an increased risk of osteoporotic fractures, although the number of studies included for the meta-analysis was small. Larger-scale better-designed studies that report the occurrence of osteoporotic fracture in breast cancer patients are needed in the future to determine which factors are associated with an increased risk of osteoporotic fracture in patients with breast cancer. 


\section{DECLARATIONS}

\section{Acknowledgments}

This research was supported by a grant ( $\mathrm{HI} 18 \mathrm{C} 0284)$ from the Korea Health Technology R\&D Project through the Korea Health Industry Development Institute (KHIDI) funded by the Ministry of Health \& Welfare, Republic of Korea.

\section{Ethics approval and consent to participate Not applicable.}

\section{Conflict of interest}

No potential conflict of interest relevant to this article was reported.

\section{ORCID}

Jun-II Yoo https://orcid.org/0000-0002-3575-4123

Young-Kyun Lee https://orcid.org/0000-0001-6564-4294

Jung-Wee Park https://orcid.org/0000-0002-4515-1895

Yong-Chan $\mathrm{Ha}$ https://orcid.org/0000-0002-6249-0581

Kyung-Hoi Koo https://orcid.org/0000-0001-5251-2911

\section{REFERENCES}

1. National Institutes of Health. Cancer stat facts: Female breast cancer. 2019 [cited by 2019 Nov 26]. Available from: https://seer.cancer.gov/statfacts/html/breast.html

2. Yap YS, Lu YS, Tamura K, et al. Insights into breast cancer in the east vs the west: A review. JAMA Oncol 2019. http:// dx.doi.og/10.1001/jamaoncol.2019.0620.

3. Howlader N, Altekruse SF, Li Cl, et al. US incidence of breast cancer subtypes defined by joint hormone receptor and HER2 status. J Natl Cancer Inst 2014. http://dx.doi.og/10.1093/ jnci/dju055.

4. Goldhirsch A, Wood WC, Coates AS, et al. Strategies for subtypes-dealing with the diversity of breast cancer: highlights of the St. Gallen International Expert Consensus on the Primary Therapy of Early Breast Cancer 2011. Ann Oncol 2011;22:1736-47.

5. Dowsett M, Cuzick J, Ingle J, et al. Meta-analysis of breast cancer outcomes in adjuvant trials of aromatase inhibitors versus tamoxifen. J Clin Oncol 2010;28:509-18.

6. Mauri D, Pavlidis N, Polyzos NP, et al. Survival with aromatase inhibitors and inactivators versus standard hormonal therapy in advanced breast cancer: meta-analysis. J Natl
Cancer Inst 2006;98:1285-91.

7. Becker T, Lipscombe L, Narod S, et al. Systematic review of bone health in older women treated with aromatase inhibitors for early-stage breast cancer. J Am Geriatr Soc 2012; 60:1761-7.

8. Hadji P. Aromatase inhibitor-associated bone loss in breast cancer patients is distinct from postmenopausal osteoporosis. Crit Rev Oncol Hematol 2009;69:73-82.

9. Lee SJ, Kim KM, Brown JK, et al. Negative impact of aromatase inhibitors on proximal femoral bone mass and geometry in postmenopausal women with breast cancer. Calcif Tissue Int 2015;97:551-9.

10. Kyvernitakis I, Rachner TD, Urbschat A, et al. Effect of aromatase inhibition on serum levels of sclerostin and dickkopf-1, bone turnover markers and bone mineral density in women with breast cancer. J Cancer Res Clin Oncol 2014; 140:1671-80.

11. Coleman RE, Banks LM, Girgis Sl, et al. Skeletal effects of exemestane on bone-mineral density, bone biomarkers, and fracture incidence in postmenopausal women with early breast cancer participating in the Intergroup Exemestane Study (IES): a randomised controlled study. Lancet Oncol 2007;8:119-27.

12. Goss PE, Ingle JN, Martino S, et al. Randomized trial of letrozole following tamoxifen as extended adjuvant therapy in receptor-positive breast cancer: updated findings from NCIC CTG MA.17. J Natl Cancer Inst 2005;97:1262-71.

13. Cuzick J, Sestak I, Baum M, et al. Effect of anastrozole and tamoxifen as adjuvant treatment for early-stage breast cancer: 10-year analysis of the ATAC trial. Lancet Oncol 2010;11:1135-41.

14. Rabaglio M, Sun Z, Price KN, et al. Bone fractures among postmenopausal patients with endocrine-responsive early breast cancer treated with 5 years of letrozole or tamoxifen in the BIG 1-98 trial. Ann Oncol 2009;20:1489-98.

15. Forbes JF, Cuzick J, Buzdar A, et al. Effect of anastrozole and tamoxifen as adjuvant treatment for early-stage breast cancer: 100-month analysis of the ATAC trial. Lancet Oncol 2008:9:45-53.

16. Amir E, Seruga B, Niraula S, et al. Toxicity of adjuvant endocrine therapy in postmenopausal breast cancer patients: a systematic review and meta-analysis. J Natl Cancer Inst 2011;103:1299-309.

17. Taxel P, Faircloth E, Idrees S, et al. Cancer treatment-induced bone loss in women with breast cancer and men with pros- 
tate cancer. J Endocr Soc 2018;2:574-88.

18. Melton LJ, 3rd, Hartmann LC, Achenbach SJ, et al. Fracture risk in women with breast cancer: a population-based study. J Bone Miner Res 2012;27:1196-205.

19. Shamseer L, Moher D, Clarke M, et al. Preferred reporting items for systematic review and meta-analysis protocols (PRISMA-P) 2015: elaboration and explanation. BMJ 2016; 354:i4086.

20. Fraenkel M, Geffen DB, Novack V, et al. Breast cancer survivors are at an increased risk for osteoporotic fractures not explained by lower BMD: a retrospective analysis. NPJ Breast Cancer 2015;1:15010.

21. Hsieh E, Wang Q, Zhang R, et al. Vertebral fractures among breast cancer survivors in China: a cross-sectional study of prevalence and health services gaps. BMC Cancer 2018;18: 104.

22. Kanis JA, McCloskey EV, Powles T, et al. A high incidence of vertebral fracture in women with breast cancer. $\mathrm{Br} J$ Cancer 1999;79:1179-81.

23. Tsai $\mathrm{CH}$, Muo $\mathrm{CH}$, Tzeng $\mathrm{HE}$, et al. Fracture in asian women with breast cancer occurs at younger age. PLoS One 2013; 8:e75109.

24. Lo JC, Burnett-Bowie SA, Finkelstein JS. Bone and the perimenopause. Obstet Gynecol Clin North Am 2011;38:50317.

25. de Cremoux P, Diéras V, Poupon MF, et al. Tamoxifen and aromatase inhibitors in the treatment of breast cancer in menopausal women: pharmacological and clinical aspects. Bull Cancer 2004;91:917-27.

26. Hofbauer LC, Rachner TD, Hamann C. From bone to breast and back - the bone cytokine RANKL and breast cancer. Breast Cancer Res 2011;13:107.

27. Kalder M, Hadji P. Breast cancer and osteoporosis - management of cancer treatment-induced bone loss in postmenopausal women with breast cancer. Breast Care (Basel) 2014;9:312-7.

28. Sheean $P$, Liang $H$, Schiffer $L$, et al. Assessing the prevalence of compromised bone health among overweight and obese African-American breast cancer survivors: a casecontrol study. J Cancer Surviv 2016;10:21-30.

29. Boman A, Kokkonen H, Ärlestig L, et al. Receptor activator of nuclear factor kappa-B ligand (RANKL) but not sclerostin or gene polymorphisms is related to joint destruction in early rheumatoid arthritis. Clin Rheumatol 2017;36:100512.
30. Lee J, Park C, Kim HJ, et al. Stimulation of osteoclast migration and bone resorption by C-C chemokine ligands 19 and 21. Exp Mol Med 2017;49:e358.

31. Fata JE, Kong YY, Li J, et al. The osteoclast differentiation factor osteoprotegerin-ligand is essential for mammary gland development. Cell 2000;103:41-50.

32. Tremollieres FA, Ceausu I, Depypere $H$, et al. Osteoporosis management in patients with breast cancer: EMAS position statement. Maturitas 2017;95:65-71.

33. Manolagas SC. From estrogen-centric to aging and oxidative stress: a revised perspective of the pathogenesis of osteoporosis. Endocr Rev 2010;31:266-300.

34. Maeda SS, Lazaretti-Castro M. An overview on the treatment of postmenopausal osteoporosis. Arq Bras Endocrinol Metabol 2014;58:162-71.

35. Yue W, Wang JP, Li Y, et al. Effects of estrogen on breast cancer development: Role of estrogen receptor independent mechanisms. Int J Cancer 2010;127:1748-57.

36. Hsu LH, Chu NM, Kao SH. Estrogen, estrogen receptor and lung cancer. Int J Mol Sci 2017. http://dx.doi.og/10.3390/ ijms18081713.

37. Nishimukai A, Higuchi T, Ozawa H, et al. Different patterns of change in bone turnover markers during treatment with bone-modifying agents for breast cancer patients with bone metastases. Breast Cancer 2017;24:245-53.

38. Banfi G, lorio EL, Corsi MM. Oxidative stress, free radicals and bone remodeling. Clin Chem Lab Med 2008;46:1550-5.

39. Domazetovic V, Marcucci G, lantomasi T, et al. Oxidative stress in bone remodeling: role of antioxidants. Clin Cases Miner Bone Metab 2017;14:209-16.

40. Wauquier F, Leotoing L, Coxam V, et al. Oxidative stress in bone remodelling and disease. Trends Mol Med 2009;15: 468-77.

41. Baek KH, Oh KW, Lee WY, et al. Association of oxidative stress with postmenopausal osteoporosis and the effects of hydrogen peroxide on osteoclast formation in human bone marrow cell cultures. Calcif Tissue Int 2010;87:22635.

42. Fontani F, Marcucci G, lantomasi T, et al. Glutathione, Nacetylcysteine and lipoic acid down-regulate starvationinduced apoptosis, RANKL/OPG ratio and sclerostin in osteocytes: involvement of JNK and ERK1/2 signalling. Calcif Tissue Int 2015;96:335-46.

43. Ueno T, Yamada M, Igarashi Y, et al. N-acetyl cysteine protects osteoblastic function from oxidative stress. J Biomed 
Mater Res A 2011;99:523-31.

44. Hecht F, Pessoa CF, Gentile LB, et al. The role of oxidative stress on breast cancer development and therapy. Tumour Biol 2016;37:4281-91.

45. Yu T, Di G. Role of tumor microenvironment in triple-negative breast cancer and its prognostic significance. Chin J Cancer Res 2017;29:237-52.

46. Chen Y, Zeng C, Zhan Y, et al. Aberrant low expression of p85alpha in stromal fibroblasts promotes breast cancer cell metastasis through exosome-mediated paracrine Wnt10b. Oncogene 2017;36:4692-705.

47. Bussard KM, Mutkus L, Stumpf K, et al. Tumor-associated stromal cells as key contributors to the tumor microenvironment. Breast Cancer Res 2016;18:84.

48. Ettinger B, Pressman A, Sklarin P, et al. Associations between low levels of serum estradiol, bone density, and fractures among elderly women: the study of osteoporotic fractures. J Clin Endocrinol Metab 1998;83:2239-43.

49. Buzdar AU, Robertson JF, Eiermann W, et al. An overview of the pharmacology and pharmacokinetics of the newer generation aromatase inhibitors anastrozole, letrozole, and exemestane. Cancer 2002;95:2006-16.

50. Pfeilschifter J. Role of cytokines in postmenopausal bone loss. Curr Osteoporos Rep 2003;1:53-8.

51. Shimodaira K, Fujikawa H, Okura F, et al. Osteoblast cells (MG-63 and HOS) have aromatase and 5 alpha-reductase activities. Biochem Mol Biol Int 1996;39:109-16.

52. Miki Y, Suzuki T, Hatori M, et al. Effects of aromatase inhibitors on human osteoblast and osteoblast-like cells: a possible androgenic bone protective effects induced by exemestane. Bone 2007;40:876-87. 


\section{SUPPLEMENTARY MATERIAL}

Supplementary Appendix 1. Detailed search strategies for each database. MeSH terms, search terms, and combinations of the 2 were used for each database search

\begin{tabular}{|c|c|c|c|c|}
\hline Database & \multicolumn{3}{|c|}{ Detailed search strategies } & $\begin{array}{l}\text { Records } \\
\text { founded }\end{array}$ \\
\hline MEDLINE/PubMed & \multicolumn{3}{|c|}{$\begin{array}{l}\text { ("breast cancer"[All Fields] OR ("Breast Neoplasms"[MeSH]) OR "Unilateral Breast Neoplasms"[MeSH] OR } \\
\text { "Mastectomy, Segmental"[MeSH]) AND ("osteoporosis"[All Fields] OR "osteoporosis"[MeSH Terms] OR "bone } \\
\text { density"[MeSH Terms] OR ("bone"[All Fields] AND "density"[All Fields]) OR "bone density"[All Fields] OR } \\
\text { ("bone"[All Fields] AND "mineral"[All Fields] AND "density"[All Fields]) OR "bone mineral density"[All Fields]) } \\
\text { AND ("fractures, bone"[MeSH Terms] OR "bone fractures"[All Fields] OR "fracture"[All Fields]) }\end{array}$} & 777 \\
\hline \multirow[t]{2}{*}{ EMBASE } & \multicolumn{3}{|c|}{$\begin{array}{l}\text { ('breast cancer'/exp OR 'mastectomy'/exp OR 'breast cancer' OR 'breast neoplasm' OR 'mastectomy') AND } \\
\text { ('fragility fracture'/exp OR 'osteoporotic fracture') }\end{array}$} & 816 \\
\hline & ID & Search Hits & Results & \\
\hline \multirow{11}{*}{$\begin{array}{l}\text { Cochrane Central } \\
\text { Register of Con- } \\
\text { trolled Trials }\end{array}$} & $\# 1$ & MeSH descriptor: [Breast Neoplasms] explode all trees & 11,134 & \multirow[t]{11}{*}{568} \\
\hline & \#2 & MeSH descriptor: [Mastectomy] explode all trees & 1,446 & \\
\hline & \#3 & MeSH descriptor: [Unilateral Breast Neoplasms] explode all trees & 7 & \\
\hline & \#4 & 'mastectomy' or 'breast cancer' or 'breast neoplasm' & 28,236 & \\
\hline & \#5 & $\# 1$ OR \#2 OR \#3 OR \#4 & 28,517 & \\
\hline & \#6 & MeSH descriptor: [Osteoporosis] explode all trees & 3,685 & \\
\hline & $\# 7$ & MeSH descriptor: [Osteoporotic Fractures] explode all trees & 236 & \\
\hline & \#8 & MeSH descriptor: [Bone Density] explode all trees & 4,369 & \\
\hline & $\# 9$ & 'osteoporotic fracture' or 'osteoporosis' or 'bone mineral density' & 11,702 & \\
\hline & $\# 10$ & \#6 OR \#7 OR \#8 OR \#9 & 12,265 & \\
\hline & $\# 11$ & $\# 5$ AND \#10 & 671 & \\
\hline
\end{tabular}

Ultimately, 2,161 records were found, 777 from MEDLINE/PubMed, 816 from EMBASE, and 568 from the Cochrane Library. Studies were further selected according to the inclusion criteria listed in the material and methods (Fig. 1). 
